\begin{tabular}{|c|c|}
\hline Citation & $\begin{array}{l}\text { W. Leterme, I. Jahn, P. Ruffing, K. Sharifabadi and D. Van Hertem, } \\
\text { "Designing for High-Voltage dc Grid Protection: Fault Clearing Strategies } \\
\text { and Protection Algorithms," in IEEE Power and Energy Magazine, vol. 17, } \\
\text { no. 3, pp. 73-81, May-June } 2019 .\end{array}$ \\
\hline Archived version & @2019 IEEE \\
\hline \multirow[t]{2}{*}{ Published version } & DOI: 10.1109/MPE.2019.2897188 \\
\hline & $\begin{array}{l}\text { URL (IET Digital Library): } \\
\text { https://ieeexplore.ieee.org/document/8694082 }\end{array}$ \\
\hline \multirow[t]{2}{*}{ Author contact } & \\
\hline & $\begin{array}{l}\text { Willem Leterme willem.leterme@kuleuven.be } \\
\text { tel: } \pm 3216328697\end{array}$ \\
\hline
\end{tabular}




\title{
"Designing for High-Voltage dc Grid Protection: Fault Clearing Strategies and Protection Algorithms
}

\author{
Willem Leterme, Ilka Jahn, Philipp Ruffing, Kamran Sharifabadi and Dirk Van Hertem
}

\section{Introduction}

Protection of HVDC grids requires a different approach compared with $A C$ power system protection and is one of the major challenges that must be resolved before the realization of large-scale HVDC grids using equipment by multiple vendors. HVDC grid protection, essential for the safe and reliable operation of the HVDC grid, entails the appropriate detection and fault clearing of DC side short-circuit faults (or in short, "DC faults"). In this context, fault clearing refers to interruption of the DC fault current and the isolation of the faulted component. Fault current interruption is much more complex in HVDC grids compared with AC systems as DC fault currents have no naturally recurring zero-crossings and, without countermeasures, quickly increase to values that are unacceptable for the power-electronic components. By contrast, the technologies used within HVDC grids offer options for fault clearing beyond the commonly used approach of using circuit breakers in the existing AC systems.

\section{Functional requirements for HVDC grid protection}

For a cost-effective and reliable future power system with HVDC grids, the design of HVDC grid protection must start with the knowledge of the likelihood of faults occurring in the system, their impact on the system and the type of equipment available to clear them. The HVDC grid protection design thus stands in close relationship with the overall design of the HVDC grid itself and with the selection of the components within the HVDC grid. Within this context, we refer to the overall design of the HVDC grid in the choices made in HVDC grid structure, i.e., number of terminals, radial or meshed connection of terminals, power rating of AC-DC nodes, as well as choice of grid configuration and grounding, such as high-impedance grounded symmetric monopole or lowimpedance grounded asymmetric monopole or bipole. With the selection of its components, we refer to the technology used for transmission lines, converters and fault clearing equipment. The combination of all these aspects determines the probability of faults in the system and their impact without HVDC grid protection.

The impact of the fault on the system in terms of overcurrent or overvoltage depends on the combination of fault type and on the grounding and configuration of the HVDC grid. For pole-to-pole faults, irrespective of the grounding and configuration, DC fault currents quickly increase and reach a high steady-state value in the absence of any protection. The impact of pole-to-ground faults depends on the type of grounding: for a lowimpedance grounded grid, prospective fault currents are high, whereas for a high-impedance grounded system, prospective overvoltages on the healthy poles are high (Figure 1). 


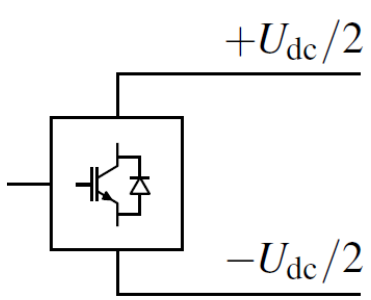

(a)

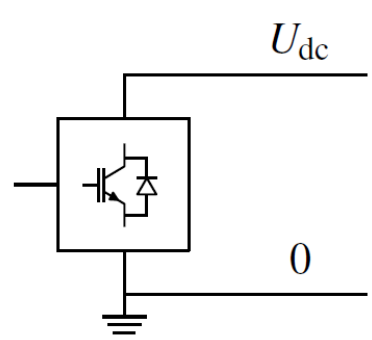

(b)

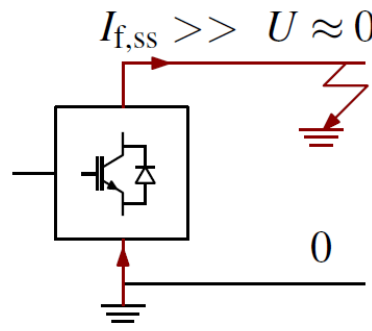

(f)

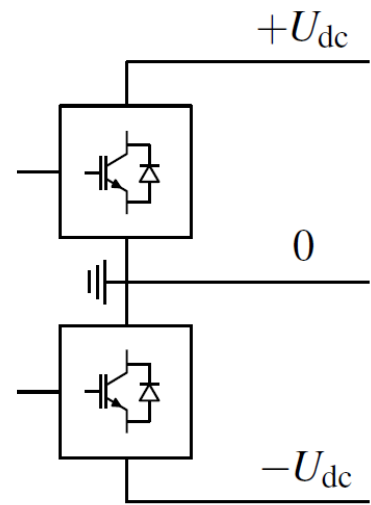

(c)

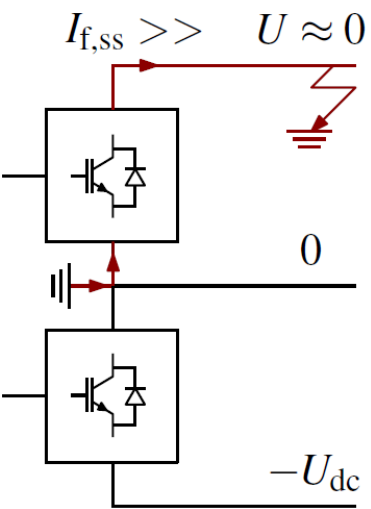

(g)

Figure 1 Three possible configurations for HVDC systems indicating voltages during normal operation and prospective fault voltages and currents during pole-to-ground faults ((a,e) symmetric monopole, $(b, f)$ asymmetric monopole with metallic return, $(c, g)$ : bipole with metallic return).

The faults occurring in the system can be grouped into several categories indicating the acceptability or unacceptability of their probability and impact, which combine into risk (Figure 2). The resulting design of HVDC grid protection will largely depend on the outcome of this risk assessment and will determine the final impact of faults on the system. For instance, it is conceivable that the protection of a symmetric monopolar cable grid differs considerably from that of a bipolar grid making use of overhead lines. In the first case, the HVDC grid protection might make use of HVDC circuit breakers with low current interruption capability or might not use HVDC circuit breakers at all to deal with the rare fault occurrence and the high likelihood of permanent faults. In the second case, it might make sense to provide HVDC circuit breakers at both ends of all lines to quickly isolate the more often recurring faults and to provide for automatic reclosing of the HVDC circuit breakers in case of non-permanent faults. 


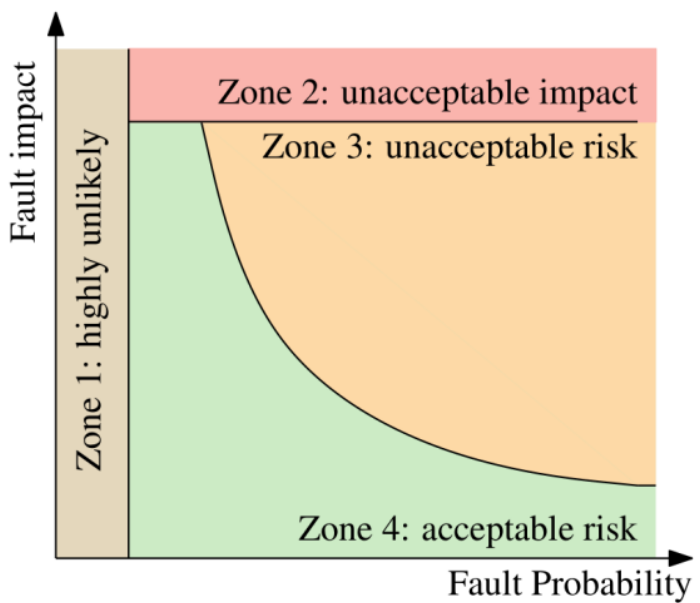

Figure 2 Example classification of power system faults and impact based on RTE's "Mémento de la sûreté du système électrique".

Although a set of specific functional requirements for HVDC grid protection can only be compiled once the HVDC grid design has been determined, the overall objectives for every HVDC grid protection scheme are the same: the HVDC grid protection should ensure continuity of secure power system operation and avoid damage to power system components in case faults occur. For short-circuit faults, this means that the HVDC grid protection should detect the faults, interrupt the short-circuit currents, isolate the faulted component and restore the system to a secure operation state. The protection should perform these functions without causing unwanted AC or DC system instabilities. In addition, it should avoid damage to equipment and property and it should guarantee safety for personnel and people.

A set of functional requirements for interacting with the connected AC system can be defined based on the constraints for its secure operation and based on the constraints of its components. Each AC system grid code defines a maximum power imbalance which imposes a limit to the secure operation of the system. For instance, this maximum power imbalance is specified in the ENTSO-E (European) grid code as being $3 \mathrm{GW}$ in continental Europe for an unspecified amount of time, or in UK as $1.8 \mathrm{GW}$ to avoid a frequency deviation outside the range of $49.5-50.5 \mathrm{~Hz}$ for 60 seconds. The HVDC grid protection should thus prevent causing a power imbalance in the connected AC system that exceeds that maximum value. In addition to the maximum power imbalance, possible functional requirements for HVDC grid protection relate to the transient stability of the connected AC systems or to damages to its components.

Within the HVDC grid, functional requirements for the HVDC grid protection can be based on continuity of the HVDC grid operation itself (if required) or from the limits of its components. At present, there is no HVDC grid code that defines the constraints within which secure operation is achieved, and the following suggestions are given for illustration purposes only. The HVDC grid protection can be required to keep the voltage at converter terminals within certain limits, such that they can remain connected. Such a "converter DC fault ride through," however, might not necessarily imply that every converter remains in an active switching state or retains the capability of supporting the AC system during the entire fault duration. The HVDC grid protection should furthermore avoid damage to the power-electronic components and other equipment. At present, for VSC HVDC point-to-point connections, the most critical components are the converter power electronic switches, i.e., the Insulated-Gate Bipolar Transistors (IGBTS). In future HVDC grids, HVDC circuit breakers (if any) could also form a limiting factor as these might be required to absorb a large amount of energy during fault current interruption.

\section{Technology assisting in clearing DC faults}

\section{- $\quad$ AC circuit breakers}


In current VSC HVDC point-to-point schemes, AC circuit breakers are installed in a converter station as the primary DC fault interrupting device given that the AC/DC converter itself, i.e., either a two-level or half-bridge modular multilevel converter (MMC), has no DC fault blocking capability. For these types of converters, a fault current path from the AC to the DC side always exists via the anti-parallel diodes within the converter's submodules (Figure 3). Therefore, the AC circuit breakers eliminate the AC contribution to the DC fault and typically interrupt the $A C$ current associated with the DC fault within a few cycles of the fundamental frequency. After eliminating the AC current contribution, the DC current passively decays to zero in a time interval that depends on converter topology and system parameters.

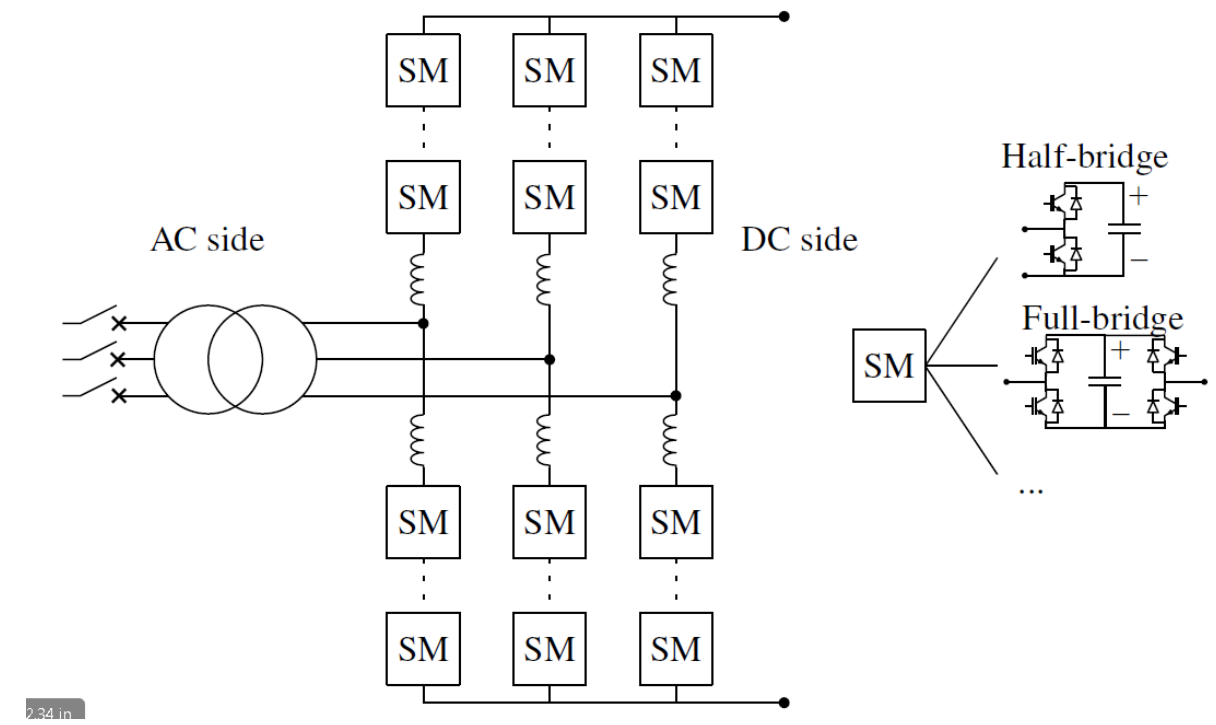

Figure 3 Schematic of a Modular Multilevel Converter comprising half-bridge or full-bridge submodules

\section{- $\quad$ HVDC circuit breakers}

HVDC circuit breakers are the DC counterparts of AC circuit breakers and can interrupt both nominal and a short circuit current up to their short circuit rating. Typically, the HVDC circuit breakers must interrupt currents within the range of five to fifteen $\mathrm{kA}$ within a time interval of several milliseconds. They are more complex compared with AC circuit breakers because they must deal with DC currents, which have no naturally recurring zero crossings. To interrupt these non-zero currents, the HVDC circuit breakers consist of several parallel paths, performing the functions of current interruption itself and absorbing the energy present in the inductive elements of the circuit. Figure 4 illustrates these paths, where the upper path typically comprises a mechanical switch and forms the path for normal conduction, the middle path is an auxiliary path to aid in interrupting fault currents and the lower path is an auxiliary path for energy absorption, typically consisting of metal oxide varistors. The HVDC circuit breaker's operation typically relies on a succession of actions, which depend on the technology used. Resonant circuit breakers making use of mechanical breakers and resonant circuits that induce current zero crossings in the mechanical breaker (Fig. 4 (a) and (b)). Because of their slow clearing time, passive resonant breakers are not appropriate for interrupting short-circuit currents in VSC based HVDC systems. HVDC circuit breakers based on a combination of power electronics and mechanical breakers in the normal conduction path, e.g., so-called hybrid HVDC circuit breakers, typically involve the use of power electronics to avoid arcs in the mechanical breakers (Fig. 4 (c)). Each of the technologies pushed forward by the manufacturers entail advantages and disadvantages in terms of speed, on-state losses, cost of components, physical dimensions, maximum current interruption capability or overall reliability and simplicity of components used. HVDC circuit breakers are not yet commercially available, but prototypes have been tested and found to perform in the range of expected requirements. Note that these prototypes all require fault current limiting equipment, as explained below. 

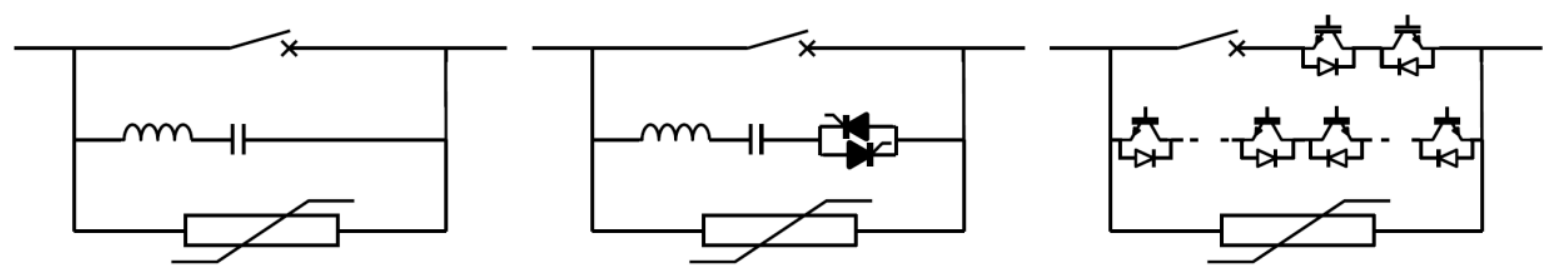

Figure 4 Conceptual DC switchgear designs: (a) passive resonant circuit breaker, (b) active resonant circuit breaker, (c) hybrid circuit breaker.

\section{- $\quad$ Fault blocking converters}

In contrast to converters without fault blocking capability, converters with fault blocking capability have the ability to block the fault current contribution from the AC system to the DC fault. These converters rely on converter submodules, which have the capability of inserting voltages of positive and negative polarity, unlike the half-bridge submodule which can only insert voltages of positive polarity (see Figure 3). As such, they are able to insert a voltage opposing the $A C$ system voltage contribution in the fault current path connecting the $A C$ to the DC system. This enables them to block the fault current contribution from the AC to the DC side without the need for AC or DC circuit breakers. The most established converter with fault blocking capability is the fullbridge MMC (Figure 3), which will see its first application in the German Ultranet project. Nevertheless, there are other promising converter configurations, which allow for blocking and control of DC fault currents while having reduced losses during normal operation compared with the full-bridge MMC. Examples of such configurations are hybrid MMC configurations making use of a combination of half- and full-bridge submodules, or alternative topologies such as the Alternative Arm Converter. The fault blocking capability may be achieved in a controlled or uncontrolled manner. A major advantage of controlled instead of uncontrolled DC fault blocking is the uninterrupted reactive power controllability of the converter, which allows the converter to operate in STATCOM mode during the entire fault clearing process.

\section{- $\quad$ DC/DC converters}

$D C / D C$ converters, proposed to transform the DC voltage from one level to another, may also be able to limit or even interrupt the fault current contribution from one to the other side. The capability of the DC/DC converter to block the transfer of fault currents depends on its topology. All topologies of DC/DC converters using an intermediate $\mathrm{AC}$ stage, thereby providing galvanic isolation between both sides, can block the propagation of fault current from one side to the other, irrespective of the fault blocking capability of the AC/DC converters used. In case of direct DC/DC conversion, the topologies are generally able to block fault current propagation in one direction whereas only certain types of topologies are able to block the fault current propagation in both directions. For instance, to achieve bidirectional fault blocking capability with modular multilevel type DC/DC converter, submodules with fault blocking capability must be used.

\section{- $\quad$ Fault current limiters}

At present, HVDC grid protection invariably requires equipment that limits the rate-of-rise or the magnitude of the DC fault current. Fault current limiting equipment may take various forms: inductors in series with the circuit (typically air-core), active fault current limiting through converters with fault blocking capability, HVDC circuit breakers with fault current limiting capability or superconducting fault current limiters. Inductors in series with the circuit only limit the rate-of-rise of the fault current and act only as fault current limiter in conjunction with equipment to interrupt the DC fault current, such as HVDC circuit breakers. These inductors may be placed directly in series with the DC circuit breakers or can also be found within the arms of the AC/DC converters. $A C / D C$ converters with controlled fault blocking capability can control the fault current to limit it to a desired fault current level instead of reducing the DC fault current entirely to zero. Certain types of HVDC circuit breakers are cable of actively limiting the current, e.g., the ones making use of controllable power electronic modules. Superconducting fault current limiters use a component which is in superconducting mode during normal operation. Therefore, it presents a low impedance to the circuit. During faults, the superconducting 
component is driven out of superconducting mode, resulting in the loss of superconducting capabilities, and thereby presents a high impedance to the circuit. Fault current limiting equipment can be installed in series with the transmission lines. In this manner, they are able to limit both the transmission line discharge currents as well as the contributions from the ac/dc converters. Fault current limiters that are located in series with the ac/dc converters do not affect the line discharge currents.

\section{- High-speed switches}

DC high-speed switches can be used to quickly isolate a faulted line from the remaining DC network, operating only under near-zero voltage and current conditions. Therefore, these high-speed switches do not need the capability to interrupt fault currents. However, depending on the application, these switches might be required to interrupt small residual currents in the grid, which for instance result from passive discharge of capacitive or inductive grid components. In case these residual currents have zero crossings, these high-speed switches may make use of traditional AC circuit breaker technology. In the case without current zero crossings, the high-speed switches must provide a sufficiently high counter-voltage or have an auxiliary circuit that creates a zero crossing, e.g., a passive resonant circuit as used in load transfer breakers in classic point-to-point HVDC connections.

\section{Classification and characterization of fault clearing strategies for HVDC grids}

HVDC grid protection does not necessarily use the conventional approach as for AC system protection. In the conventional approach to AC system protection, circuit breakers are placed throughout the system and are used to simultaneously interrupt the fault current and isolate the faulted component. This has led to a fault clearing strategy dividing the power system into zones containing grid elements such as transformers or transmission lines. In case of a fault, the protection scheme disconnects and de-energizes only the zone containing the fault. Given the different types of equipment available for HVDC grid protection and given the characteristics of this equipment, alternative options for the selective fault clearing strategy exist. In the alternative options, the protection zones used for fault current interruption do not necessarily coincide with the components that should be isolated. These fault clearing strategies can be classified in terms of "extent of the HVDC grid which is de-energized," an approach followed in the CIGRE technical brochure TB 739, or described in terms of "action of the converter station" an approach followed in the CENELEC document CLC/TS 50654-1.

In CIGRE TB739, fault-clearing strategies are divided into three main philosophies. In the first philosophy, nonselective fault clearing, the entire HVDC grid is completely de-energized prior to isolation of the faulted component under near zero voltage and current conditions. The faulted component should be identified during or after grid de-energization and may be automatically isolated using high-speed switches. After the faulted component is isolated, the remaining part of the HVDC grid is re-energized before power flow can resume. In the second philosophy, partially selective fault clearing, the HVDC grid is subdivided into several protection zones. Here the faulted zone is first quickly isolated from the healthy zones of the grid. This requires that equipment capable of interrupting DC fault currents is present at all boundaries of each protection zone. Thereafter, the faulted element within the faulted zone is isolated as in a non-selective philosophy before the remaining portion of the initially faulted zone is re-energized and reconnected to the healthy parts of the grid. The third philosophy, fully selective fault clearing, adopts an approach to DC fault clearing similar to the conventional approach from AC systems.

In the approach followed by CENELEC, three main concepts applied within a certain protection zone are defined based on the impact of DC faults within a protection zone on all AC and DC points of connection, i.e., (i) continuous operation (CO), (ii) temporary stop (TS) and (iii) permanent stop (PS). For each of these three concepts, a typical "fault separation time", i.e., the time at which recovery of the active power flow can start, is defined. These three main concepts are extended to a total of five concepts when considering the availability of reactive power during DC fault separation. For continuous operation, the exchange of active power with DC systems (connected at a DC point of connection) and active or reactive power with AC systems (connected at an $A C$ point of connection) must remain controllable during the entire fault separation process, resulting in fault separation times in the order of a few milliseconds. In the temporary stop concept, the disruption of active power exchange with DC systems (connected at a DC point of connection) or active and reactive power 
exchange with $\mathrm{AC}$ systems (connected at an $\mathrm{AC}$ point of connection) must remain short such that the $\mathrm{AC}$ or $\mathrm{DC}$ system at a point of connection does not enter into an abnormal operating mode. As such, the temporary stop concept is expected to have a fault separation time of a few hundred milliseconds. For permanent stop, the disruption of active or active and reactive power may cause the transmission systems at the point of connection to enter an abnormal mode of operation, resulting in fault separation times in the order of seconds.

Each fault clearing strategy entails different consequences to the DC system and the connected AC systems and, consequently, functional requirements for the HVDC grid protection differ with the adopted strategy. In the fully selective philosophy, or in those zones making use of the "continuous operation" concept, the HVDC grid protection should primarily ensure that the DC voltage remains within acceptable limits that keep the AC-DC converters connected. In non-selective strategies, the DC voltage inherently collapses, and the HVDC grid protection is mainly required to clear the fault and allow for the later restoration of the system in a manner that does not endanger the secure operation of the connected AC system. The choices for the protection concepts are in this respect either a permanent or a temporary stop. In partially selective strategies, the HVDC grid protection must keep the DC voltage in the healthy zones of the system, as well as not endanger the secure operation of the AC system. Therefore, the healthy zones of the system should adopt the continuous operation concept. The faulted zone takes either the permanent or the temporary stop, depending on the constraints imposed by the grid codes of the connected AC system or systems.

\section{Fault clearing strategies for HVDC grids}

\section{Non-selective with AC circuit breakers}

This strategy relies on the AC circuit breakers on the AC side of the AC-DC converters to interrupt the DC fault current. In terms of protection concepts, all converter stations adopt the "permanent stop" -concept as defined by CENELEC. As soon as a fault is detected using the sensors at a converter terminal, a trip order is sent to the $A C$ circuit breakers to interrupt the fault current. When the AC circuit breakers of all AC-DC converters in the grid have opened, the AC fault current contribution to the DC fault current is eliminated and the DC fault current and DC voltage passively decay to a value close to zero. Thereafter, the faulted component is isolated using disconnect switches or high-speed switches (HSS) connected at each end of the DC lines. Re-energizing the AC-DC converters in the new post-fault situation can be achieved through reclosing the AC circuit breakers, restoring the $\mathrm{DC}$ voltage to within the normal operation range, and restoring the power flow to securely operate the HVDC grid. This strategy is illustrated in the DC1-system in Figure 5a, where the AC circuit breakers of the half-bridge modular multilevel converters are used to interrupt the fault current, and high-speed switches or disconnect switches are used to isolate the faulted equipment.

\section{$\underline{\text { Non-selective with fault blocking converters }}$}

In this strategy, converters with fault blocking capability are used to quickly stop the fault current contribution from the AC system to the HVDC grid through a joint action of all converters. Consequently, the HVDC grid quickly de-energizes and the fault currents decay to values close to zero. Thereafter, the faulted line is isolated under near-zero voltage and current conditions with a DC high-speed switch with residual DC current interruption capability. Once the faulted line is isolated, the converters restore the DC voltage and subsequently, the power flow. The DC2-system in Figure 5a illustrates this concept. Actively restoring the DC voltage from zero voltage requires use of converters with controlled fault blocking capability. The active voltage restoration can then occur faster compared with converters without controlled fault blocking capability or without fault blocking capability at all. Hence, in a non-selective strategy using converters with controlled fault blocking capability, DC voltage recovery can occur faster compared with the non-selective strategy using AC circuit breakers in conjunction with converters without fault blocking capability. Therefore, in this strategy, the actions of the converters with controlled fault blocking capability fall under the protection concept "temporary stop".

\section{Partially selective with HVDC circuit breakers or DC/DC converters}

This strategy is similar to the non-selective fault clearing strategies in the sense that fault currents are interrupted by de-energizing the HVDC grid and that the faulted component is isolated under voltages and currents close to zero, but significantly differs from those strategies in the sense that only a part of the HVDC 
grid is de-energized. As such, these strategies must rely on HVDC circuit breakers or DC/DC converters placed in between the protection zones to isolate the faulted zone of the grid from the healthy ones. In the healthy zones of the grid, the DC voltage must be kept within those boundaries between which the AC/DC converters are able to ensure continuity of the power flow. In the faulted zones of the grid, any approach belonging to the nonselective protection philosophies can be used to interrupt the DC fault current and to isolate the faulted component. After fault clearing, the faulted zone of the HVDC grid is re-energized and reconnected to the healthy zones of the HVDC grid. In Figure $5 b$, a partially selective fault clearing strategy is adopted to achieve connection of systems $D C_{1}$ and $D C_{2}$, if an outage of the entire system $\left(D C_{1}+D C_{2}\right)$ is, e.g., unacceptable to the connected $\mathrm{AC}$ grid $\mathrm{AC}_{1}$.

\section{$\underline{\text { Fully Selective with HVDC circuit breakers }}$}

For a selective fault clearing strategy, HVDC circuit breakers are located at the end of each line to interrupt the fault current and simultaneously isolate the faulted line (Figure 5c). This strategy is similar to the conventional approach to AC system protection. In this strategy, all converters adopt the "continuous operation" concept as defined by CENELEC, which implies that the fault clearance sufficiently quickly to avoid collapse of the DC voltage. In case the symmetric monopole configuration is used, the HVDC grid protection must also rebalance the pole voltages in cases of pole-to-ground faults. For pole rebalancing, either special DC chopper circuits or converters allowing for injection of zero sequence AC currents into the DC side can be used.

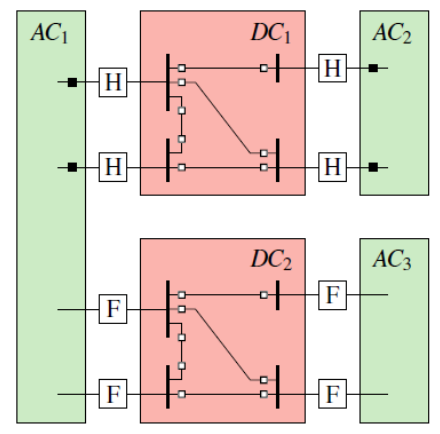

(a)

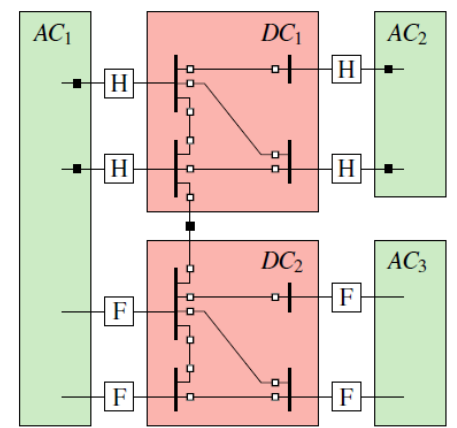

(b)

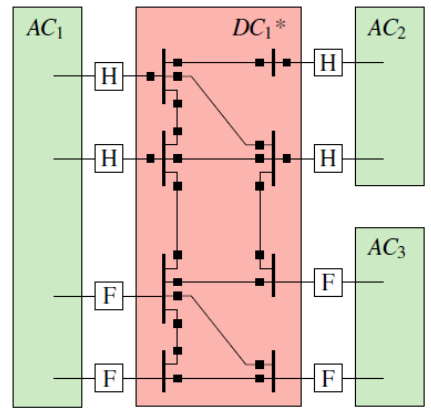

(c)

$\mathrm{H}$ F Half/Full-bridge converter - Circuit Breaker $\square$ (High-speed) Switch

Figure 5 Example fault clearing strategies in an extended HVDC grid: (a) non-selective fault clearing using AC circuit breakers $\left(D C_{1}\right)$ or fault blocking converters $\left(D C_{2}\right)$, (b) partially selective fault clearing using HVDC circuit breakers or a $D C / D C$ converter and (c) fully selective fault clearing using HVDC circuit breakers.

\section{$\underline{\text { Discussion }}$}

HVDC grid protection can be designed using a wide variety of fault clearing strategies, as illustrated with the examples above. The choice of fault clearing strategy is not straightforward, and depends on many factors such as desired overall reliability of the power system, relative power rating of the HVDC grid compared to the connected AC system, cost of fault clearing equipment or adaptability of the adopted strategy to system expansion. The non-selective strategies only consider secure operation of the connected AC systems and entail the lowest cost of components at the DC side. These strategies require considerable effort in the restoration of the HVDC grid and grid restoration times should be adapted to meet the AC system constraints. The selective strategies consider the protection of the HVDC grid itself by keeping the DC voltage within an acceptable range. These strategies require a higher investment cost in terms of fault clearing equipment on the DC side, i.e., the HVDC circuit breakers at the end of each transmission line, but may require less effort in restoring the power flow compared with non-selective strategies. The partially selective strategies face a trade-off in limiting the extent of the HVDC grid disconnected against investment in DC-side fault clearing equipment. The final choice 
for a certain strategy will depend on the investment costs associated with the required fault clearing equipment, the probability of each type of fault and the desired impact of fault clearing on the HVDC grid itself and on the connected AC systems. It is conceivable that the desired protection philosophy provides a higher speed of operation and a higher selectivity of fault clearing as the HVDC grid grows in size. While each of the fault clearing strategies has specific consequences for the design and operation of HVDC grids, it is not inconceivable that systems arise that use multiple strategies, e.g. for backup and primary protection or for different sections of a single grid.

\section{HVDC grid protection algorithms}

The functional requirements for protection algorithms used to detect faults and to identify their location in HVDC grids are largely the same as their AC counterparts. Requirements can be set on parameters such as speed, reliability or sensitivity. The main challenge for HVDC grid protection algorithms is to achieve the desired reliability, in terms of security and dependability, within a very small amount of time. In particular, protection algorithms must make the correct decisions on whether to trip fault clearing equipment or not within the first milliseconds after fault detection based upon the measured voltages and currents. Increased operating time of the protection algorithm might lead to a more reliable decision, but also leads in general to an increased overall fault clearing time, which is unwanted given the quickly increasing DC fault current. Important aspects for the choice and tuning of protection algorithms are the HVDC grid topology, the converter technology, system grounding, measurement, and operating points.

This section focuses on algorithms for primary line protection in HVDC grids. Fault detection for selective fault clearing strategies is more challenging than for non-selective strategies, so the focus is on algorithms for selective fault detection. This does not prevent using the same algorithms for non-selective fault clearing strategies. The protection algorithms can be implemented using principles based on local measurements only or using principles based on communication of measurements from distinct locations in the grid.

Protection algorithms without communications rely only on locally measured voltages and currents. These algorithms can be classified into those detecting a fault during a transient and those monitoring a signal for a certain amount of time.

Most of the proposed algorithms without communications detect faults during the transient following the fault event. Among these algorithms are voltage derivative, current derivative, combinations of voltage and current derivative, and travelling wave algorithms. The algorithms determine whether the fault is inside the protection zone using the shape of the wave front following a fault. To differentiate wave shapes for internal and external faults requires knowing an electrical distance. This electrical distance is typically driven by the series inductors required for the HVDC circuit breakers, which act as low-pass filters on the wave fronts generated by external faults. Remote faults on long cables are more difficult to detect than closer faults as a result of wave front distortion and attenuation during propagation on the transmission line. The basic fault detection methods based on transient voltages and currents can be further refined using signal processing methods to improve their function in a noisy environment. Communication-less protection algorithms based on undervoltage and overcurrent are more suited to complement main protection or backup protection. The respective undervoltage or overcurrent criterion have a fixed time requirement. In contrast with the fastest algorithms, these two criteria do not rely on the shape of the waveforms during the fault transient.

Communication-based protection algorithms combine information from both line ends to make a tripping decision, and therefore require a communication channel to exchange logic signals or measured quantities from both line ends. The communication channel must allow for high-speed communication and most likely would rely on fiber optic cables. The algorithms can be classified into those communicating a status (directional comparison), and those communicating actual measurement data (differential). The protection zones are specific for communication-based protection algorithms and they do not need DC line inductors separating the protection zones.

Directional comparison can be implemented as a tripping scheme or a blocking scheme. In both cases, a fault in the forward direction is detected at the local line end, which needs to be confirmed by information from the remote line end. In a tripping scheme, the presence of the fault is confirmed by presence of a tripping signal 
from the remote line end. A tripping signal is issued by the remote line end if the measurements at that end indicate a fault in the forward direction, i.e., in the direction of the protection zone. In a blocking scheme, the presence of a fault is confirmed by absence of a blocking signal from the remote line end. A blocking signal would indicate detection of a fault in the reverse direction at the remote end of the protection zone. The tripping scheme introduces the largest delays in a directional comparison scheme. These delays occur for a fault at the local end of the protection zone. While the fault is perceived almost instantaneously by the local measurements, the algorithm must wait for signals communicated from the remote line end to make a tripping decision.

Differential line protection compares the currents or traveling waves seen at both line ends. The basic principles of traveling wave differential protection originally developed for AC overhead line systems are applied to HVDC systems. However, the algorithm might need an adaptation for cable systems, due to the larger influence of wave distortion and attenuation in cable systems. For these algorithms, the delay caused by the wave propagation is subtracted from the communication delay, which favours a high speed of operation. Since these algorithms rely on exchange of measured quantities rather than logical signals, they impose a larger communication burden compared with directional algorithms.

In summary, communication-less algorithms have the advantage of fast fault detection due to the absence of communication delays but face difficulties in detection of remote faults. By contrast, communication-based algorithms can detect remote faults while having an acceptable communication delay. Therefore, a combination of communication-based and communication-less algorithms might be suitable for protecting long lines.

a)

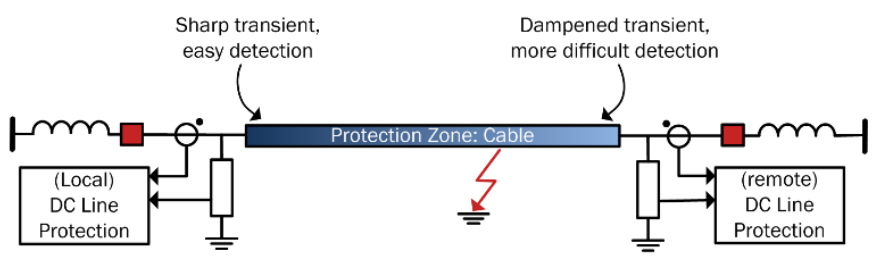

b)

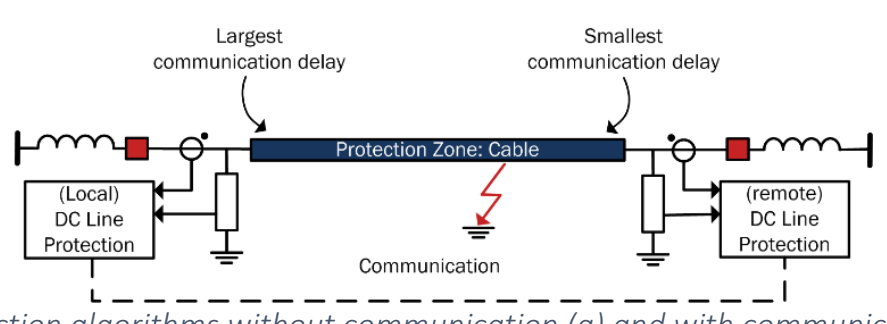

Figure 6 Comparison of protection algorithms without communication (a) and with communication (b), comments refer to local DC line protection.

\section{Summary}

The design of a reliable and effective HVDC grid protection scheme depends on the system characteristics on the one hand and on the strategy used for fault clearing on the other hand. The system characteristics determine the requirements on the protection, by determining the relationship between the probability of faults and their impact and by setting constraints on secure system operation. The strategy used for fault clearing determines which technology can be used (e.g., using HVDC circuit breakers or not) and determines the final impact of a fault on the system and its components. For HVDC grid protection, fault clearing strategies can be classified into three main philosophies, i.e., non-selective, partially selective, and fully selective. The impact of the fault on an AC or DC system can be determined based on the actions which the AC/DC converters perform during fault clearing. In all cases, the fault clearing strategies benefit from fast fault detection, and in case of a fully selective strategy, also a fast identification of the fault. The overview of protection algorithms given in this article shows that these algorithms mainly operate on traveling waves, use a scheme without communication or differential or directional comparison scheme using communication. In the former, the 
algorithms must rely on an impedance between the protection zones, which for HVDC grids may be provided by an inductor in series with the HVDC circuit breaker. In the latter two cases such impedances are not needed, but the algorithms must rely on a fast communication channel, such as a dedicated fiber optic cable.

\section{Further reading}

CIGRÉ Joint Working Group B4/B5-59, "Local control and protection of HVDC grids", TB739, 2017

Promotion, "Deliverable 4.2: Broad comparison of fault clearing strategies for DC grids," [Online]. Available: https://www.promotion-

offshore.net/fileadmin/PDFs/D4.2_Broad_comparison_of_fault_clearing_strategies_for_DC_grids.pdf

D. Van Hertem, O. Gomis-Bellmunt and J. Liang (eds.), "HVDC Grids for Offshore and Supergrid of the Future," Hoboken, NJ: J. Wiley \& Sons, 2016

I. Jahn, N. Johannesson and S. Norrga, "Survey of Methods for Selective DC Fault Detection in MTDC Grids," in IET ACDC 2017, Manchester, 2017.

\section{Biographies}

Willem Leterme and Dirk Van Hertem are with the University of Leuven (KU Leuven)/EnergyVille, Belgium. Ilka Jahn is with the Royal Institute of Technology (KTH) Stockholm, Sweden.

Philipp Ruffing is with RWTH Aachen, Germany.

Kamran Sharifabadi is with Equinor, Norway.

The authors would like to acknowledge the contributions of the members of Work Package 4 within the European H2020 Project PROMOtioN. The work was funded by Horizon 2020 PROMOTioN (Progress on Meshed HVDC Offshore Transmission Networks) project under Grant Agreement No. 691714. 